6. Stovner LJ, Hagen K, Jensen R, et al. The global burden of headache: a documentation of headache prevalence and disability worldwide. Cephalalgia 2007;27:193-210.

7. Available at: http://www.who.int/healthinfo/global_ burden_disease/estimates_country/en/index.html. Accessed October 23, 2011.

8. Schwedt TJ, Shapiro RE. Funding of research on headache disorders by the National Institutes of Health. Headache 2009;49:162-169.

9. Available at: http://www.alz.org/documents_custom/ FINAL_Trajectory_Report_Release-EMB_5-11-10.pdf. Accessed October 23, 2011.

10. Anad S, Hanson K. Disability-adjusted life years: a critical review. J Health Econ 1997;16:685-702.

\section{CAROTID STENOSIS: TO REVASCULARIZE, OR NOT TO REVASCULARIZE: THAT IS THE QUESTION}

Bart M. Demaerschalk, Scottsdale, AZ; George Howard, Birmingham, AL; Thomas G. Brott, Jacksonville, FL: In their editorial, Drs. Marquardt and Barnett ${ }^{1}$ contend that because the CREST trial ${ }^{2}$ grouped symptomatic and asymptomatic patients together, the trial denied information about the benefit of endarterectomy (CEA) and stenting (CAS) in these separate conditions. We respectfully disagree.

In CREST, ${ }^{2}$ a prespecified aim was estimation of modification of the treatment effect by symptomatic status assessed through inclusion of the interaction term in the proportional hazards model as a single variable. By that method, there was no evidence of a differential effect for patients with symptomatic or with asymptomatic carotid stenosis for any of the primary or secondary outcomes. ${ }^{2}$ For example, Drs. Marquardt and Barnett may take issue with the inclusion of periprocedural myocardial infarction as a component of the primary outcome in CREST. However, we found no evidence of treatment effect by symptomatic status for stroke and death. Furthermore, after the periprocedural period the incidences of ipsilateral stroke with CAS and CEA were similarly low ( $2 \%$ and $2.4 \%$, respectively; $\mathrm{p}=0.85)$.

Our conclusions differ substantially from those of Drs. Marquardt and Barnett. Both endarterectomy and stenting have an important role to play in the management of carotid stenosis. Clinicians and their patients now have 2 safe and effective options ${ }^{3}$ for revascularization of the carotid artery.

Editor's Note: The authors of the article were offered the opportunity to respond but declined.

Copyright (ㄷ 2012 by AAN Enterprises, Inc.

1. Marquardt L, Barnett HJM. Carotid stenosis: to revascularize, or not to revascularize: that is the question. Neurology 2011;77:710-712.

2. Brott TG, Hobson RW, Howard G, et al. Stenting versus endarterectomy for treatment of carotid-artery stenosis. N Engl J Med 2010;363:11-23.

3. Department of Health \& Human Services. Food and Drug Administration. P040012/S34 RX Acculink Carotid Stent System PMA. Available at: http://www.accessdata.fda.gov/ cdrh_docs/pdf4/P040012S034a.pdf. Accessed October 6, 2011.

\title{
CORRECTION
}

Determinants of survival in progressive multifocal leukoencephalopathy

In the article "Determinants of survival in progressive multifocal leukoencephalopathy" by A. Marzocchetti et al. (Neurology ${ }^{\circledR}$ 2009;73:1551-1558), there is an error in the labeling of the $y$-axis in figures 3 and 4 . The $y$-axis should read "Cumulative probability of survival categorized by the presence of IRIS" in figure 3 and "Cumulative probability of survival categorized by CD4 count at baseline" in figure 4. 